\title{
Methyl Mercury, Adipokines, 3T3-L1 Cells and Diabetes
}

\section{Chauhan $\mathbf{S}^{1,2}$, Dunlap $\mathrm{K}^{1,2}$ and Duffy $\mathbf{L K}^{1 *}$}

${ }^{1}$ Department of Chemistry and Biochemistry, University of Alaska Fairbanks, USA

${ }^{2}$ Institute of Arctic Biology, University of Alaska Fairbanks, USA

${ }^{*}$ Corresponding author: Lawrence K Duffy, Department of Chemistry and Biochemistry, University of Alaska Fairbanks, AK 99775-6160, USA, Tel: 907-4747525; Email: lkduffy@alaska.edu

\section{Review Article \\ Volume 3 Issue 4}

Received Date: November 01, 2018

Published Date: November 20, 2018

DOI: $10.23880 /$ act-16000141

\section{Abstract}

Diabetes is a contributor to morbidity across the globe and is often associated with obesity and metabolic syndrome. In addition to genetic and lifestyle factors, environmental factors such as metals and persistent organic pollutants may increase the severity or lower the threshold of these conditions. Studies are showing an association between these contaminants and both insulin sensitivity and glucose transport. In cell culture, mercury and methyl mercury are toxic to adipocytes and impact the secretion of cytokines and adipokines. We propose a research model using contaminants like methyl mercury on adipocytes to enhance the existing knowledge on the mechanistic influence of adipokines and reactive oxygen species on 3T3-L1 cell functioning. With this enhanced signaling model, anti-inflammatory agents could be tested at the biochemical level and lead to studies in animal models. Prospective model studies on mixtures of contaminants can contribute to better understanding about the development or severity of diabetes.

Keywords: Adiponectin; Resistin; Methyl Mercury; 3T3-L1 cells; Diabetes

Abbreviations: MeHg: Methyl Mercury; MetS: Metabolic Syndrome; VEGF: Vascular Endothelial Growth Factor; ROS: Reactive Oxygen Species; WAT: White Adipose Tissue.

\section{Introduction}

Methyl mercury (MeHg) is historically known to pose a threat to the ecosystem. MeHg, a potent neurotoxin, bioaccumulates and biomagnifies through the ecosystem and eventually to human beings [1]. 80\%-90\% of organic mercury in humans is from fish and shellfish intake [2]. Arctic communities residing in rural Alaska rely highly on fish as a staple food [3]. Also, MeHg crosses the human placenta and can impair the developing fetus [4]. Recent epidemiological studies suggest a correlation between
MeHg exposure and eventual development of type 2 diabetes and hypertension [5,6].

Many studies in the neurotoxicity of MeHg have been conducted to investigate the underlying mechanism [710]. The potential effect of MeHg on other organ or cell types has not been extensively studied. In 2003, Barnes et al. looked at the effect of inorganic mercuric chloride on the process of adipogenesis which suggested mercury exposure can inhibit the differentiation process of preadipocytes [11]. Later, in 2005, Barnes, et al. also concluded that the addition of mercuric chloride to the differentiated 3T3-L1 cells increased glucose transport [12].

To the best of our knowledge, only one study exists which has examined the effect of organic mercury, MeHg, 


\section{Advances in Clinical Toxicology}

on the adipocytes, the specialized cells of the adipose tissue. In studying the cytokine Vascular Endothelium Growth Factor (VEGF) expression by 3T3-L1 cells, Vertigan, et al. observed that an exposure of $100 \mathrm{ng} / \mathrm{ml}$ $(0.4 \mathrm{uM})$ of $\mathrm{MeHg}$ is cytotoxic to adipocytes [13]. Additionally, they found that $0.4 \mathrm{uM} \mathrm{MeHg}$ exposure elevates the VEGF secretion during later stages of differentiation.

However, the effect of MeHg on the mature adipocytes and on adipokines associated with the development of metabolic syndrome (Met S), such as adiponectin and resistin, have not been well studied. Moreover, no study exists on mitigating the negative effects of MeHg exposure associated with the diet. Cell culture studies on 3T3-L1 cell line provide an experimental model for studying the effects of $\mathrm{MeHg}$ exposure and other contaminants on adipose tissue. MeHg has a high affinity for sulfhydral protein groups leading to S-mercuration. S-mercuration of cellular proteins is assumed to be involved in the mechanism underlying MeHg toxicity [8]. In the process of metabolism, MeHg undergoes reactions that increase the release of free radicals such as Reactive Oxygen Species (ROS) [2]. ROS causes oxidative stress and lipid peroxidation which has been suggested as a cause for the insulin resistance associated with type 2 diabetes [14]. Insulin resistance and dysfunctional insulin signaling lead to the onset of type 2 diabetes. Since low levels of $\mathrm{MeHg}$ are present in many foods, and is fat soluble, it is reasonable to investigate its relationship to adipokines. A cell culture model that can investigate $\mathrm{MeHg}$ mixtures with low levels of other contaminants would be useful [15].

The significance of a model focusing on the cell culture hierarchical level is threefold. First, there is a greater precision in measurement of the interaction of the adipokines in controlled experiments. Secondly, there is an increasing literature linking oxidative stress to diabetes and Met S. Thirdly, the cell culture system is easily adaptable to using multiple stressors such as mixtures of metals and endocrine disruptors. Such a design and the measure of the changes in various adipokines levels would give a more realistic picture of the impact of environmental exposure. The response of the adipokines in this model would provide the basis for new strategies in disease management.

Since there is an increasing variety of the type of metals which the general population is exposed too, a significant public health issue understanding the impact of various metals, as well as mixtures, on the etiology of hypertension and diabetes. Studies in model systems are needed to clarify the underlying mechanisms such as the role of the balance of antioxidants $[15,16]$.

\section{Adipokines and Anti-Inflammatory Agents}

Adipokines such as adiponectin and resistin are proteins which are secreted from the adipocytes and are potential markers for metabolic syndrome [17]. Antiinflammatory agents may mitigate the effect of $\mathrm{MeHg}$ by reducing the amount of ROS formed. A natural compound derived from black tea, possess anti- inflammatory properties and it might be a potential therapeutic candidate for reducing inflammation [18]. Theaflavin-3,3'digigallate possess several active properties, one of which is the ability to fight ovarian cancer $[19,20]$. Natural products like organic tea compounds might protect individuals exposed to the normal concentration of $\mathrm{MeHg}$ found in Alaskan subsistence foods [21].

Obesity has also been linked with type 2 diabetes [2224]. Preliminary investigations regarding the effects of MeHg exposure on adipocytes will enhance the existing knowledge in this area of research. A central question would be "If MeHg increases basal ROS levels, would it interfere with adiponectin and resistin secretion patterns, thereby alternating insulin sensitivity and regulation of glucose transport?" Natural compounds such as theaflavin-3,3'-digigallate should be tested to observe their effect on MeHg interference on adipokines secretion.

Alaskans eat, on average, more fish than the average American, since many living in rural Alaska have to rely on fish for subsistence [25-29]. Obesity rates are rising among Alaska Native populations and the amount of mercury found in the environment in Arctic regions has also been rising [30]. Little research is performed on the effect of MeHg exposure on organs other than brain. Thus far, Barnes et al and Vertigan, et al. have studied the effects on the 3T3 -L1 cells. Vertigan, et al. found that $\mathrm{MeHg}$ exposure of $100 \mathrm{ng} / \mathrm{ml}$ is cytotoxic to the $3 \mathrm{~T} 3 \mathrm{~L} 1$ cells and also increase VEGF secretion during later stages of differentiation [11-13]. Studies to observe the effect of $\mathrm{MeHg}$ on ROS levels and the effect of theaflavin-3,3'digigallate, or other anti-oxidants would contribute to the knowledge characterizing the system.

Epidemiological studies suggest a correlation between the mercury exposure and eventual development of obesity and/or diabetes [5,6]. About 2 out of every 3 Alaskan adults are now overweight or obese [31]. The likelihood of American Indian and Alaska Native adults to have diagnosed diabetes compared with non-Hispanic whites was 2.3 times higher in 2009 (16.1\% vs. 7.1\%) 
[32]. However this correlation remains controversial as some studies suggests no such correlation between mercury and the development of any metabolic syndrome [33]. Regardless, more investigations are needed to more fully understand the effects of MeHg on adipose tissue.

Adipose tissue is a major endocrine systems present in the human body. Initially, it was considered only for storing excess fat tissue, but now that myth has been put to rest and adipose tissue is shown to be actively involved in regulation processes. Recent studies have shown that adipose tissue produces large amounts of biologically active and specific proteins also known as adipokines which play key roles in glucose and energy metabolism $[17,34]$.

Adipose tissue is made up of highly specialized cells known as adipocytes, used for the storage and release of lipids. Other cell types in adipose tissue include blood cells, endothelial cells, pericytes and adipose precursor cells [35]. In recent studies, adipose tissue and adipokines were found to be involved in the pathogenesis of type 2 diabetes [36-38]. The common cell type used for in vitro studies for the phenomenon of adipogenesis and adipokines are the 3T3-L1 cell line, a well-characterized adipocyte line from mice which can acquire an adipocytelike phenotype. During the differentiation process, 3T3-L1 cells can be induced to differentiate under controlled laboratory conditions using a standard differentiation protocol and are widely accepted as a physiologically faithful in vitro representation of adipogenesis [11-13,39].

Our knowledge about the functions of adipose tissue is widening over time. Adipose tissue secretes proteins generally known as adipokines to signal different functions across the body [40-41]. Adipokines such as adiponectin and resistin are potential additional biomarkers for metabolic syndrome [17]. Adiponectin is an adipokine secreted exclusively from the adipocyes with one of its major roles in energy metabolism $[42,43]$. It stimulates fatty acids oxidation, decreases plasma triglycerides and increases glucose sensitivity [44]. It also acts as an anti-inflammatory, anti-atherogenic, and antioxidative factor [45]. Lower levels of adiponectin may lead to metabolic syndromes like insulin resistance, obesity, type 2 diabetes [46,47]. Higher levels may lead to anorexia nervosa [48].

On the other hand, resistin is a relatively new and poorly studied adipokine with biological properties opposite to adiponectin $[17,44]$. It is produced in the stromovascular fraction of adipose tissue and blood monocytes. Human resistin is $12.5-\mathrm{kDa}$ protein, which contains 108 amino acids. It circulates in human blood as a dimeric protein linked by a disulfide bond. Resistin circulates in high levels in diabetic mice models, and it is suggested that resistin is the adipokine that links obesity to type 2 diabetes [50,51]. Also, resistin is an inflammatory marker of atherosclerosis in humans [52]. The adiponectin- resistin ratio has widely been suggested by various researchers to be an indicator of metabolic risk for obesity $[17,44,53]$. The secretion levels adipokines, like adiponectin and resistin, may be associated with risk of development of hypertension, type 2 diabetes and the metabolic syndrome $[6,16]$.

In this paper, we suggest potential association of $\mathrm{MeHg}$ with adipokine profiles in 3T3-L1 cells. The exposure to MeHg might be influenced by other stressors which would be investigated in combination to observe any synergistic interactions of $\mathrm{MeHg}$ and other stressors. Pancreatic betacells are sensitive to ROS and MeHg induces beta cell apoptosis, but 3T3-L1 cells are less characterized [16,54]. Management of antioxidant levels could be a useful treatment for human health programs. Using antioxidants to counteract high exposure to $\mathrm{MeHg}$ would be a appropriated approach to population wide studies and treatment of diabetes $[6,18]$. A fuller understanding will facilitate the introduction of targeted diet-based interventions as treatments.

\section{Conclusion}

Research on the effect of contaminant exposure such as MeHg should supply baseline data and address the value of antioxidant dietary supplements as a therapeutic approach of dietary $\mathrm{MeHg}$ exposure on the function of adipose tissue. The roles of adipokines are numerous but we are focusing on the role of contaminants in energy and fat metabolism as they are directly related to obesity and metabolic syndrome. Exposure to a contaminant or mixture may lead to change in secretion patterns of adiponectin and resistin. Imbalanced ROS levels have been detected in WAT of type 2 diabetics or Met S.

An association between mitochondrial dysfunction, oxidative stress and carbonylated proteins may play critical roles in insulin resistance. High ROS levels could lead to adipocyte hypertrophy, altered metabolism, and dysregulated adipokine secretion. Basal levels of ROS are required for the differentiation of preadipocytes into adipocyte and their normal functioning. However, diminished or excessive levels of ROS levels may contribute to WAT dysfunction following insulin resistance [55,56]. 
Research is needed to develop models to determine the effect of a normal level of $\mathrm{MeHg}$ exposure on adipocytes. This understanding will add data to the debate about mercury or other contaminants and their role at the biochemical level in metabolic syndrome. Specifically, this type of research will further develop a model system to link specific environmental contaminants to metabolic syndrome and associated diseases $[6,15]$.

Barnes and his colleagues investigated the effect of inorganic mercury chloride on adipogenesis and glucose transport [11,12]. Vertigan, et al. showed increased VEGF secretion from differentiated cells due to $\mathrm{MeHg}$ exposure [13]. Their findings provide a platform for further studying $\mathrm{MeHg}$ species as a potential modulator of metabolic processes in adipocytes. The idea of using natural food in a model anti-oxidant system to study the mitigating effects on adipokine secretion will increase the possibility of a potential neutraceutical treatment options for insulin resistance [57]. Using a defined antiinflammatory compound would advance the current common approach of testing complex extracts and mixtures [15].

Also, since pollutants are increasing in the environment, the regulatory implications of this research would allow for fine tuning the criteria levels for water and food regulations. The few studies on complex mixtures have suggested that both additive and synergistic effects occur with multi-toxicant exposure. From a regulatory perspective, these impacts would require a review and possible lowering of the acceptable exposed dose in a food source. Studies in a standardized cell culture system allows for better comparison between toxicants.

\section{Acknowledgements}

We wish to acknowledge support from the University of Alaska, Fairbanks, Department of Chemistry and Biochemistry and Alzheimer Disease Resource Agency of Alaska.

\section{References}

1. (2018) Mercury in Your Environment. US Environmental Protection Agency. Mercury study report to Congress.

2. Hong Y, Kim Y, Lee KE (2012) Methyl mercury Exposure and Health Effects. J Prev Med Public Health 45(6): 353-363.
3. Lemire M, Kwan M, Laouan-Sidi A, Muckle G, Pirkle C, et al. (2015) Local country food sources of methyl mercury, selenium and omega-3 fatty acids in Nunavik, Northern Quebec. Sci Total Environ 509510: 248-259.

4. Mahaffey KR (1999) Methyl mercury: A new look at the risks. Public Health Reports 114(5): 397-413.

5. He K, Xun P, Liu K, Morris S, Reis J, et al. (2013) Mercury Exposure in Young Adulthood and Incidence of Diabetes Later in Life: The CARDIA Trace Element Study. Diabetes Care 36(6): 1584-1589.

6. Wu W, Jiang S, Zhao Q, Zhang K, Wei X, et al. (2018) Environmental exposure to metals and the risk of hypertension: A cross-sectional study in China. Environ Pollut 233: 670-678.

7. Weiss B (2007) Why Methyl mercury Remains a Conundrum 50 Years after Minamata. Toxicol Sci 97(2): 223-225.

8. Kanda H, Shinkai Y, Kumagai Y (2014) S-Mercuration of cellular proteins by methylmercury and its toxicological implications. J Toxicol Sci 39(5): 687700.

9. Kerper LE, Ballatori N, Clarkson TW (1992) Methyl mercury transport across the blood-brain barrier by an amino acid carrier. Am J Physiol 262(5).

10. Kumagai $Y$, Kanda H, Shinkai $Y$, Toyama T (2013) The Role of the Keap1/Nrf2 Pathway in the Cellular Response to Methyl mercury. Oxid Med Cell Longev 2013: 1-8.

11. Barnes DM (2003) Effects of Inorganic $\mathrm{HgCl}_{2}$ on Adipogenesis. Toxicol Sci 75(2): 368-377.

12. Barnes DM, Kircher EA (2005) Effects of mercuric chloride on glucose transport in 3T3-L1 adipocytes. Toxicol in Vitro 19(2): 207-214.

13. Vertigan T, Dunlap K, Reynolds A, Duffy L (2017) Effects of Methylmercury exposure in 3T3-L1 Adipocytes. AIMS Environmental Science 4(1): 94111.

14. Borza C, Muntean D, Dehelean C, Savoiu G, Serban C, et al. (2013) Oxidative Stress and Lipid PeroxidationA Lipid Metabolism Dysfunction. Lipid Metabolism. 


\section{Advances in Clinical Toxicology}

15. Magueresse-Battistoni BL, Vidal H, Naville D (2018) Environmental Pollutants and Metabolic Disorders: The Multi-Exposure Scenario of Life. Frontiers in Endocrinology 9: 582 .

16. Chen YW, Huang CF, Tsai KS, Yang RS, Yen CC, et al. (2006) Methylmercury Induces Pancreatic $\beta$-Cell Apoptosis and Dysfunction. Chem Res Toxicol 19(8): 1080-1085.

17. Zhang J, Kho P (2015) Adiponectin, Resistin and Leptin: Possible Markers of Metabolic Syndrome. Endocrinology \& Metabolic Syndrome $4(4)$.

18. Wu Y, Jin F, Wang Y, Li F, Wang L, et al. (2017) In vitro and in vivo anti-inflammatory effects of theaflavin3,3-digallate on lipopolysaccharide-induced inflammation. European Journal of Pharmacology 794: 52-60.

19. Gao Y, Rankin GO, Tu Y, Chen YC (2015) Theaflavin-3, 3-digallate decreases human ovarian carcinoma OVCAR-3 cell-induced angiogenesis via Akt and Notch-1 pathways, not via MAPK pathways. Int J Oncol 48(1): 281-292.

20. Miao M, Jiang H, Jiang B, Li Y, Cui SW, et al. (2013) Elucidation of structural difference in theaflavins for modulation of starch digestion. Journal of Functional Foods 5(4): 2024-2029.

21. Hamade AK (2014) Fish Consumption Advice for Alaskan: Risk Management Strategy To Optimize the Public's Health, pp:1-78.

22. Bays HE, González-Campoy JM, Bray GA, Kitabchi AE, Bergman DA, et al. (2008) Pathogenic potential of adipose tissue and metabolic consequences of adipocyte hypertrophy and increased visceral adiposity. Expert Rev Cardiovasc Ther 6(3): 343-368.

23. Kahn SE, Hull RL, Utzschneider KM (2006) Mechanisms linking obesity to insulin resistance and type 2 diabetes. Nature 444(7121): 840-846.

24. Murdolo G, Smith U (2006) The dysregulated adipose tissue: A connecting link between insulin resistance, type 2 diabetes mellitus and atherosclerosis. Nutrition, Metabolism and Cardiovascular Diseases 16 (Suppl 1): S35-S8.

25. Krabbenhoft DP, Sunderland EM (2013) Global change and mercury. Science 341(6153): 1457-1458.
26. Erickson PR, Lin VS (2015) Research highlights: Elucidation of biogeochemical factors influencing methyl mercury production. Environ Sci Process Impacts 17(10): 1708-1711.

27. (1990) International Program on Chemical Safety. Environmental methyl mercury: health criteria 101. Geneva: World Health Organization.

28. Nobmann ED, Byers T, Lanier AP, Hankin JH, Jackson MY (1992) The diet of Alaska Native adults: 19871988. Am J Clin Nutr 55(5): 1024-1032.

29. Ballew C, Ross A, Wells RS, Hiratsuka V, Hamrick KJ, et al. (2004) Final report on the Alaska Traditional Diet Survey. Anchorage, AK. Alaska Native Health Board pp: 1-171.

30. Makhoul Z, Krista AR, Gulati R, Luick B, Bersamin A, et al. (2010) Associations of very high intakes of eicosapentaenoic and docosahexaenoic acids with biomarkers of chronic disease risk among Yupik Eskimos. Am J Clin Nutr 91(3): 777-785.

31. Streur WJ (2014) Alaska Obesity Prevention \& Control Program .Alaska Obesity Facts, pp: 54.

32. (2012) Department of Health and Human Services, Indian Health Service Division of Diabetes Treatment and Prevention, Diabetes in American Indians and Alaska Natives, Facts at a Glance.

33. Futatsuka M, Kitano T, Wakamiya J (1996) An Epidemiological Study on Diabetes Mellitus in the Population Living in a Methyl Mercury Polluted Area. J Epidemiol 6(4): 204-208.

34. Scherer PE (2006) Adipose Tissue: From Lipid Storage Compartment to Endocrine Organ. Diabetes 55(6): 1537-1545.

35. Coelho M, Oliveira T, Fernandes R (2013) State of the art paper Biochemistry of adipose tissue: An endocrine organ. Archives of Medical Science 9(2): 191-200.

36. Zhang J, Zhang Z, Ding Y, Xu P, Wang T, et al. (2015) Adipose Tissues Characteristics of Normal, Obesity, and Type 2 Diabetes in Uygurs Population. Journal of Diabetes Research 2015: 1-6.

37. Dunmore SJ, Brown JE (2012) The role of adipokines in $\beta$-cell failure of type 2 diabetes. Journal of Endocrinology 216(1): T37-45. 


\section{Advances in Clinical Toxicology}

38. Kohlgruber A, Lynch L (2015) Adipose Tissue Inflammation in the Pathogenesis of Type 2 Diabetes. Curr Diab Rep 15(11): 92.

39. Rizzatti V, Boschi F, Pedrotti M, Zoico E, Sbarbati A, et al. (2013) Lipid droplets characterization in adipocyte differentiated 3T3-L1 cells: Size and optical density distribution. Eur J Histochem 57(3): 24.

40. Szendrodi J (2004) The adipose tissue as an endocrine organ. Acta Med Austriaca 1: 98- 111.

41. Zahorska-Markiewicz B (2006) Metabolic effects associated with adipose tissue distribution. Adv Med Sci 51: 111-114

42. Koerner A (2005) Adipocytokines: leptin-the classical, resistin-the controversial, adiponectin-the promising, and more to come. Best Pract Res Clin Endocrinol Metab 19(4): 525- 546.

43. Diez JJ (2003) The role of the novel adipocyte-derived hormone adiponectin in human disease. Eur J Endocrinol 148(3): 293-300.

44. Beltowski J (2003) Adiponectin and resistin-new hormones of white adipose tissue. Med Sci Monit 9(2): RA55-61.

45. Jonas MI, Kurylowicz A, Bartoszewicz Z, Lisik W, Jonas $M$, et al. (2017) Adiponectin/resistin interplay in serum and in adipose tissue of obese and normalweight individuals. Diabetol Metabo Syndr 9(1): 95.

46. Lago F, Dieguez C, Omez-Reino JG, Gualillo O (2007) The emerging role of adipokines as mediators of inflammation and immune responses. Cytokine and Growth Factor Rev 18(3-4): 313-325.

47. Weyer C, Funahashi T, Tanaka S (2001) Hypoadiponectinemia in obesity and type 2 diabetes: close association with insulin resistance and hyperinsulinaemia. J Clin Endocrinol Metab 86(5): 1930-1935.
48. Meier U (2004) Endocrine Regulation of Energy Metabolism: Review of Pathobiochemical and Clinical Chemical Aspects of Leptin, Ghrelin, Adiponectin, and Resistin. Clin Chem 50(9): 1511-1525.

49. Ding M, Rzucidlo EM, Davey JC (2012) Adiponectin in the heart and vascular system. Vitam Horm 90: 289319.

50. Abi B (2001) Resistin: a New Hormone That Links Obesity with Type 2. BMJ 322(7280): 193.

51. Steppan CM, Bailey ST, Bhat S (2001) The hormone resistin links obesity to diabetes. Nature 409(6818): 307-312.

52. Reilly M, Lehrke M, Wolfe M (2005) Resistin is an inflammatory marker of atherosclerosis in humans. Circulation 111(7): 932-939.

53. Lau C, Muniandy S (2011) Novel adiponectin-resistin (AR) and insulin resistance (IRAR) indexes are useful integrated diagnostic biomarkers for insulin resistance, type 2 diabetes and metabolic syndrome: A case control study. Cardiovasc Diabetol 10(1): 8.

54. Guilherme A, Virbasius JV, Puri V, Czech MP (2008) Adipocyte dysfunctions linking obesity to insulin resistance and type 2 diabetes. Nat Rev Mol Cell Biol 9(5): 367-377.

55. Castro JP, Grune T, Speckmann B (2016) The two faces of reactive oxygen species (ROS) in adipocyte function and dysfunction. Biol Chem 397(8): 709-24.

56. Meo SD, Reed TT, Venditti P, Victor VM (2016) Harmful and Beneficial Role of ROS. Oxid Med Cell Longev 2016: 1-3.

57. Wu X, Beecher GR, Holden JM, Haytowitz DB, Gebhardt SE, et al. (2004) Lipophilic and Hydrophilic Antioxidant Capacities of Common Foods in the United States. J Agric Food Chem 52(12): 4026-4037. 